\title{
ASSOCIATING AUTOMAT FOR TECHNOLOGICAL PROCESSES ADAPTIVE CONTROL ON BASED OF NEURAL NETWORKS
}

\author{
${ }^{* 1}$ A.V. Daneev, ${ }^{2}$ V.N. Sizykh \\ Irkutsk State Transport University, Russia
}

Received: $10^{\text {th }}$ December 2017, Accepted: 17th January 2018, Published: $28^{\text {th }}$ February 2018

\begin{abstract}
The problem of physical object neural control with parametric uncertain is considered. The architecture to organizations of the technological process through parallel interaction of technological modules (agents) similar one-layer neural-fuzzy control is offered. On based of the Lyapunov's direct research method of absolute stability and speed gradient method both a nonlinear algorithm of the operative education and control is designed. The developed algorithm of adaptation allows accelerating a convergence neural-fuzzy control through the neural network training in real time, carrying out preliminary procedures training and to apply an effective ways of parametrical their initialization. Through the additional feedback on control and the sliding modes organization about artificial neuron special points both the invariance property to external, parametrical and dynamic object noise is provided. At the organization similar neural network structures the Gurvitz's state matrixes condition for system linear part can't be carried out. Besides, area of admissible values of regulator's parameter is all set of real numbers. Software and hardware implementation of decisionmaking process an associating automat of adaptive control is expected to implement in informational real time systems on based of the Iu. F. Muhopad's structural model.
\end{abstract}

Key words: physical object, technological process, technological modules, agent, neural network, control, education, adaptation, absolute stability, sliding modes.

\section{Introduction}

The complex control system of difficult technical system consists of object of control and the actuation device.

In mechanical engineering object of control is the technological process (TP). TP is the part of production containing actions for change and the subsequent definition of a condition of a subject of production [1]. TP as object of management is the difficult dynamic system including a number of subsystems operations (technological modules (TM) [2]), each of which separately too can be object of management. It is noted [2] that the main complexity of management of TP consists in insufficient degree of its study, in limitation of volume and in incompleteness of measurements.

From positions of cybernetic physics [3] the technical system is a physical system with entrances and exits which functioning happens without participation of the person at the expense of the organization of feedback between her entrances and exits.

The technological module characterizes a status of transitions from a certain input to a certain output of physical system and considers set of simple technological operations in system. Number of such operations (transitions) -. The mathematical description of TM corresponds to dynamic equations of multivariate single-connected technical system (SISO - systems):. In this case we will call TM the agent [4].

Simple technological process - the process consisting of the interacting TM forming multiagentny system with the given topology of communications between agents [4-6].

Difficult technological process characterizes various statuses of transitions of physical system with number of inputs and number of outputs. Total number of transitions (difficult technological operations) is $n(n+m+l)$. The mathematical description of TM in this case corresponds to dynamic equations of multivariate multi-coupling technical system (MIMO - systems).

The analysis of literature shows [4-8] that it is possible to select two main directions of a research of difficult TP.

The first direction is based on the organization of functioning of difficult TP for rules of the simple, well studied TP on the basis of methods of the theory of attachment [7]. TP in this case represents the multi-agent system consisting of set of TM parallelized among themselves - the one-layer neural networks (NN) with the given topology of communications between agents (the associative automatic machine of the adaptive control) [6]. The second direction is based on representation of difficult TP in the form of multi-layer NN which topology is considered in dynamics of various transitions of statuses of physical system.

$\mathrm{NN}$ are of special interest at specialists in control for the reason that such networks can be presented in the form of units with inputs and outputs, suitable both for training, and for non-linear display between two spaces of finite dimensionality 
with any given accuracy. Besides, the main algorithm of training $\mathrm{NN}$ - an algorithm of the reverse distribution of an error of a signal - belongs to the class of gradient methods of the fastest descent in space of parameters and has the adaptive analogthe method of a high-speed gradient (MHSG) [3].

Therefore the further prospects of neural control [9] are connected with the indication of parallels between the classical theory of adaptive control and approaches to creation of neuroregulators (NR) on the basis of $\mathrm{NN}$ and studying the neuromorphic structures. NN are the nonlinear systems suitable for the solution of the practical tasks of control which are essentially connected with existence of nonlinear characteristics. $\mathrm{NN}$ allow to eliminate quantitative uncertainty of information as after training can due to interpolation (emulation) and extrapolation (adaptation and forecasting) an entrance - output characteristics of a physical object to give the right decision for obtaining the new information which isn't entering the training set.

However the existing schemes of neural management because of slow convergence of algorithms of adaptation are quasiadaptive with control out of the rate of management processes, or, being in fact adaptive, insufficiently reasonable because of difficulties of the analysis of working capacity, stability, quality and achievement of the goals of control [9]. Besides, classical statements of tasks of neuro-control are poorly connected with concepts of multiconnectivity and multidimensionality of real physical systems, control algorithms come down or to realization of program control with the empirical choice of quantity of layers of $\mathrm{NN}$ and number of neurons in each layer $[10,11]$, or to control of parameters of classical PID- regulator [9]. The adaptive and critical scheme which is brought closer to dynamic programming found application in modern SMART GRID technologies [12] is considered the most effective.

In paper the new approach to the combined synthesis (to synthesis in real or in the accelerated time) neuroregulators of simple technological processes directed to overcoming these difficulties is offered.

\section{Definition Problem of Neural Control}

We will consider the simple TP consisting of the $l$ interacting TM. TM have the general structure known in advance and differ only in transitions from entrance $j$ to TP exit $i$. Let each TM performs the TP certain function, and it is described by consecutive connection of the linear differential system (linearized on an interval of sampling (observation) of nonlinear system of the ordinary differential equations) of an object and the nonlinear inertialess converter (NIC) - a single-layer perseptron (artificial neuron). Such TM form a class of absolutely steady nonlinear systems $[13,14]$. The equations of TM with number $j(j=\overline{1, l})$ are

$$
\dot{x}=A x+B \sigma(t, z, u)+\xi, \quad \begin{aligned}
& \\
& z=c^{T} x, \\
& u=L z .
\end{aligned}
$$

For brevity of records of variables and parameters of the system of equations (1) - (3) we will write without index $j$. In further we believe that the system (1) shall meet requirements of existence and uniqueness of the decision; $n$-vector of uncontrollable perturbations $\xi \equiv \overrightarrow{0}$.

In formulas $(1)-(3)$ it is designated:

$x=\left(x_{1}, x_{2}, \ldots, x_{n}\right)-\mathrm{n}$ - dimensional state vector of TM with number $j$;

$u$ - Control of TM with number $j$ (the measured scalar input of system (1)) $u \in U \subset C^{1}$;

$z$ - Observation of TM with number $j$ (the measured scalar output of system (1)), $z \in R^{1}$;

$A$ - indefinite matrix of Jacobi of dimensionality constant parametricly $n \times n$;

$B=\left(B_{1}, B_{2}, \ldots, B_{n}\right)-$ Constant vector of the configured settings of NBP of dimensionality $n \times 1$; $c=\left(c_{1}, c_{2} \ldots, c_{n}\right)-$ The column vector of the set parameters of observation (regression) of dimensionality $1 \times n$;

$L$ - Scalar parametric regulator;

$\sigma(t, x, z)$ - The scalar activation function (AF) of a one-layer perseptron received by non-linear conversion of control $u$ and observation $z$ with number $j$.

The offered structure differs from the traditional diagram of the adaptive regulator (AR) in existence of NBP and the positive tight back coupling on a scalar output $z$. This structure of NN is added by the adder - "a circuit of internal back coupling" on a scalar input (a prototype - structure of the adaptive regulator (fig. 16, b) in [15, page 351]) to which there correspond the modified equations (1) for $j$-th TM

$$
\dot{x}=A x+B(u+\sigma(t, z, u))+\xi .
$$

The differential equations $\left(1^{*}\right)$ describe a wide class of objects with uncertainty and allow to isolate explosive control systems in a new class of intellectual systems of associative adaptation [6].

\section{Properties of Activation Function}

FA defines architecture of NN. Unambiguous recommendations about the choice of FA don't exist now. In the mode of training of-line the algorithm of the return distribution of an error of signal and the following FA is most effective: hyperbolic 
tangential, linear and logical sigmoidal functions of activation [9].

In the on-line mode (expeditious training and control) when the $\mathrm{NN}$ works in real time and performs functions of the adaptive regulator, we will believe that FA meets conditions [16]

$$
0 \leq z u \sigma \leq \tilde{q}_{1} \alpha z^{2}+\tilde{q}_{2} \beta u^{2}
$$

where $\quad z \in(-\infty ; \infty), \quad \tilde{q}_{2} \in[0,1], \quad \tilde{q}_{1}=1-\tilde{q}_{2}$, $\alpha \in] 0, \alpha], \beta \in[0, \beta] ; \tilde{q}_{1}, \tilde{q}_{2}$ - the indistinct coefficients defining redistribution of signals from input to output and from output to input (the $\mathrm{NN}$ operation mode) adjusted on intervals of observation; $\quad \alpha, \beta-$ weight factors of the appropriate physical dimensionality in case of variables in the right part of restrictions on $\sigma$.

$\operatorname{NBP} \sigma(\cdot)$ is defined by the right part of expression (4)

$$
\sigma(t, z, u)=\tilde{q}_{1} \alpha \frac{z}{u}+\tilde{q}_{2} \beta \frac{u}{z}
$$

Function (5) has two special points of $z=0 ; u=0$. We will consider previously them isolated [15]. As observation $z$ and the equation $u$ - scalar functions, taking into account (3) NBP (5) it is possible to present in the form

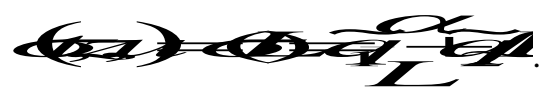

Investigating properties of function (formula (5), (6)), it is possible to notice that function:

1). Sign-certain: $\sigma(\cdot)>0$ at $z u>0 \quad(z<0, u<0$ or $z>0, u>0) ; \sigma(\cdot)<0$ at $z u<0(z>0, u<0$ or $z<0, u>0)$.

2 ). It has a special point $z=0, L=0$ in which there is a rupture of the first sort

$$
\begin{aligned}
\lim _{L \rightarrow 0^{-}} \sigma(L) & =-\infty, \lim _{L \rightarrow 0^{+}} \sigma(L)=\infty \quad \text { or } \\
\lim _{z \rightarrow 0^{-}} \sigma(t, z, u) & =-\infty, \lim _{z \rightarrow 0^{+}} \sigma(t, z, u)=\infty .
\end{aligned}
$$

$3)$. It has two points of extreme: point of maximum $L=L^{-}=-\sqrt{\frac{\tilde{q}_{1} \alpha}{\tilde{q}_{2} \beta}}$ and point of minimum $L=L^{+}=\sqrt{\frac{\tilde{q}_{1} \alpha}{\tilde{q}_{2} \beta}} \cdot$ In extremum points function $\sigma$ accepts values:

$$
\begin{gathered}
\sigma_{\max }=\sigma^{-}=-2 \sqrt{\tilde{q}_{1} \tilde{q}_{2} \alpha \beta}, \\
\sigma_{\min }=\sigma^{+}=2 \sqrt{\tilde{q}_{1} \tilde{q}_{2} \alpha \beta} .
\end{gathered}
$$

4). It has the odd and symmetric form: $L \sigma>0$ at $L \neq 0$. Really, this function changes the sign only under a condition $z u \neq 0$. At $L<0 \quad(z u<0)$ function $\sigma(\cdot)$ is negative: $\sigma<0$. At $L>0 \mathrm{FA}$ it is calculated in the I quadrant and it is positive: $L>0$ . Parameter $L \neq 0$, as - special points $z=0, u=0$.

5). At $L>L^{+}$and $L<L^{-}$function $\sigma($.$) is close to$ linear to coefficients of an inclination of straight lines $\pm \sqrt{\frac{\tilde{q}_{1} \alpha}{\tilde{q}_{2} \beta}}$.

NBP $B \sigma$ for $j$-th TM in the theory of $\mathrm{NN}$ and indistinct sets is called a single-layer perseptron with the zero shift or a fazzifikator, vector line $c^{T}$ is regressor or sensor [17]. NBP $B(u+\sigma)$ (formula (

$\left.1^{*}\right)$ ) defines single-layer perseptron with nonzero shift. NBP are basic processor elements of the associative automatic machine [6].

At adaptive approach it is considered that there is a steady internal structure of a physical object [15], but his parameters (coefficients of matrix $A$ ) are unknown. At the description of $j$-th TM it presents separable linear part with transfer function $W(p)$ (object) and nonlinearity with the characteristic $\sigma(\cdot)$. Therefore coefficients of transfer function $W(p)$ are unknown, and concerning nonlinearity partial properties of the characteristic $\sigma(\cdot)$ are specified. Besides, the vector $B$ of the adjusted weight coefficients of a single-layer perseptron is unknown.

(6) It is required to exercise operational control of $j$-th of TM by means of the adaptive parametric neuroregulator $L$.

The parallel with the diagram of the adaptive control with a self-adjustment is the basis for the offered approach: The NN configures the control settings operation of the normal controller so that an output signal $j$-th TM was supported as it is possible closer to the desirable: $\lim _{t \rightarrow \infty} x(t)=x_{*}=\overrightarrow{0}$. Such control of $\mathrm{j}$-th TM is called stabilizing one [15].

The problem of synthesis of the adaptive parametric neuroregulator is solved in three stages:

1) The selected class of non-linear systems on stability is researched;

2) The stabilizing control $u$ providing the adaptation purpose is synthesized: $\lim _{t \rightarrow \infty} x(t)=\overrightarrow{0}$;

3) Under the terms of stability the $\mathrm{NN}$ parameters are initialized.

\section{Direct Lyapunov Method of The Research Of Absolute Stability}

Stability is considered as property of the free movement of system (1) after initial deviation caused by any reasons. Not indignant movement $x_{*}=\overrightarrow{0}$ is defined by the zero solution of system (1). 
Analytical definition of a concept of Lyapunov stability is formulated as follows [16].

Definition 1. The zero solution of system (1) is steady if at the as much as small $\varepsilon>0$ there is $\delta>0$, depending from $\varepsilon$ that under entry conditions $\left|x_{i}(0)\right|<\delta, i=\overline{1, n}$, for the decision on an interval $0<t<\infty$ the condition $\left|x_{i}(t)\right|<\varepsilon, i=\overline{1, n}$ is satisfied.

If conditions of definition 1 are met and the condition $\lim _{t \rightarrow \infty} x(t)=x_{*}=\overrightarrow{0}$ is carried out, then the zero solution of system (1) asymptotically is steady. If the condition $\lim _{t \rightarrow \infty} x(t)=x *=\overrightarrow{0}$ is satisfied for any entry conditions $x(0)$, then the zero solution of system (1) is steady in general. Asymptotic stability of the zero solution of system (1) in general at any nature of nonlinearity in a certain class is defined by a concept of absolute stability.

By analogy with work [13] we will make the following hypotheses.

Hypothesis 1. Absolute stability of the zero solution of system (1) - (3) in a class of not linearities (4) requires also enough that this system asymptotically was steady at $\sigma(t, z, u)=\tilde{q}_{1} \alpha \frac{z}{u}+\tilde{q}_{2} \beta \frac{u}{z}$ for any $\tilde{q}_{2} \in[0,1]$, $\left.\left.\tilde{q}_{1}=1-\tilde{q}_{2}, \alpha \in\right] 0, \alpha *\right], \beta \in\left[0, \beta_{*}\right]$.

Hypothesis 2. Achievement of the goal of adaptation $\lim _{t \rightarrow \infty} x(t)=\overrightarrow{0}$ of differential system (1) requires also enough that her zero decision was steady in a class of not linearities (4).

In work [14] it is shown that to hypotheses close to formulated, the system of any order satisfies if her pulse function is positive. Then the problem of this class of absolutely steady systems comes down to determination of effective criteria of positivity of such functions.

The Transfer Function (TF) of a linear part of system (1) - (3) from an entrance $\sigma$ to an exit $z$ is equal

$$
W(p)=c^{T}(p I-A)^{-1} B=\frac{Q(p)}{P(p)} .
$$

Here $I-$ a single matrix of the size $n \times n$;

$P(p)=p^{n}+a_{1} p^{n-1}+\ldots+a_{n} ; Q(p)=p^{m}+a_{1} p^{m-1}+\ldots$ - polynoms for definition of poles and zero TF $W(p)$.

We will designate through $p_{1}, \ldots, p_{n}$ roots of a characteristic polynom $P(p)$ (TF poles), and through $g(t)$ - pulse transitional (weight) function

$$
g(t)=\frac{1}{2 \pi i} \int_{\operatorname{Re} p<\beta} e^{p t} \frac{Q(p)}{P(p)} d p, \quad \beta=\max _{k} \operatorname{Re} p_{k} .
$$

Theorem 1. If at non-negative pulse function ( $g(t) \geq 0$ at $t \geq 0$ ) the zero solution of system (1)(3) it is steady in general, then achievement of the goal of adaptation $\lim _{t \rightarrow \infty} x(t)=\overrightarrow{0}$ requires also enough performance of one of two conditions in a class of not linearities (4):

a) the matrix $A$ must be Gurvitz's one ( $\operatorname{Re} p_{k}<0, k=\overline{1, n}$ );

b) the zero decision has to be steady

$$
\begin{gathered}
x(0)+\left[\tilde{q}_{2} \beta L+\frac{\tilde{q}_{1} \alpha}{L}\right] B=0 \text { или } \\
\|x(0)\| \leq\left[\tilde{q}_{2} \beta L+\frac{\tilde{q}_{1} \alpha}{L}\right]\|B\| .
\end{gathered}
$$

Theorem 2. If at non-negative pulse function $(g(t) \geq 0$ at $t \geq 0)$ matrix $A+L B c^{T}$ is Gurvitz's one and roots of characteristic polynom of control $u$ have features in the left half-plane, then the zero solution of the equations $\left(1^{*}\right),(2),(3)$ is absolutely exponential steady in a class of not linearities (4). And, on the contrary, if $g(t) \geq 0$ at $t \geq 0$, the zero solution of the equations $\left(1^{*}\right),(2)$, (3) is exponential steady, then a matrix $A$ is Gurvitz's one if Gurvitz's polynom $U(p)$ of control $u$.

Corollary of the theorem 2. Achievement of the goal of adaptation $\lim _{t \rightarrow \infty} x(t)=\overrightarrow{0}$ in system $\left(1^{*}\right),(2)$,

(3) requires also enough performance of one of two conditions in a class of not linearities $u+\sigma(t, z, u)$ :

a) The matrix $A+L B c^{T}$ must be Gurvitz's one;

b) The condition of stability of the zero decision has to coincide with a condition of stability of the zero solution of the equations (1) - (3) theorems 1.

The analytical solution of system $\left(1^{*}\right),(2),(3)$ at restrictions of a look (4) has an appearance [16]

$$
x(t)=e^{\left(A+L B c^{T}\right) t}\left\{x(0)+\left[\tilde{q}_{2} \beta L+\frac{\tilde{q}_{1} \alpha}{L}\right] B\right\} . \quad \text { (8) }
$$

The proof of theorems 1, 2 is provided in work [16].

$+a_{m} T h$ hos 9 m 3. If for the system of the equations $(1)^{m}$ - (3) there is a positive sign-certain function $V(t, z, u)=\tilde{q}_{1} \alpha z^{2}+\tilde{q}_{2} \beta u^{2}$, then at NBP of a look (6) derivative $\dot{V}$ of this function is sign-certain too, but the opposite sign if conditions are at the same time satisfied 


$$
z \dot{z}<0, L \dot{L}<0 \text {. }
$$

At the same time the solution of system (1) asymptotically is steady: $\lim _{t \rightarrow \infty} x(t)=x_{*}=0$. [18].

The proof of the theorem 3 is provided in work

As points $z=0, u=0$ are special points, the sufficient condition of asymptotic stability is approximately satisfied in some area limited to vertical $L^{ \pm}$and horizontal $\sigma^{ \pm}$asymptotes of function $\sigma(L)$. This area is called area of the sliding modes [19]. At $L>L^{+}$and $L<L^{-}$function $\sigma(L)$ is close to linear dependence, and, therefore, the parametrical regulator $L$ in these areas of change of an argument is quasilinear one.

In the field of the sliding modes it is necessary to provide performance of conditions (9) of the theorem 3.

\section{Control of Neural Network on Activation Function}

We will find out in more detail what physical sense is made by the function of activation set by the formula (5) and the condition b) of theorem 1.

It is easy to notice that FA (5) contains two composed: the first composed corresponds to the return (inverse) distribution of a signal, second composed - to his direct distribution.

As observation $z$ and control $u$ in architecture of the single-layer NN which is built in the ordinary adaptive regulator are scalar functions, and special points are considered isolated, FA (5) for $j$-th is calculated by TM on a formula (6)

$$
\begin{aligned}
\sigma(t, z, u) & =\tilde{q}_{1} \frac{\alpha}{L}+\tilde{q}_{2} \beta L, \\
\tilde{q}_{2} \in[0,1], \tilde{q}_{1} & =1-\tilde{q}_{2} . \\
\text { In tasks } & \text { of control parameter } \tilde{q}_{2} \text { is }
\end{aligned}
$$
recommended to be connected with an interval of observation of an output signal $z$ which breaks on $s$ sampling periods $T_{0}: T_{0}=\frac{T-t_{0}}{s}$. During every period of sampling several training iterations are carried out. In the simplest case it is possible to accept the sampling period equal to the period of correction of the training iteration $T_{0}=T_{L}$ : and to connect at $t_{0}=0$ the period of observation of an output signal with real time: $\tilde{q}_{2}=\frac{t}{s T_{0}}, t \in\left[0, s T_{0}\right], s=1,2 \ldots$

The simple analysis of expressions (5), (6) shows that the neural network functions in three modes:

A. If $\tilde{q}_{2}=0$ then initialization of the $\mathrm{NN}$ parameters is carried out; the network studies previously $\left(\tilde{q}_{1}=1\right)$ on an algorithm of the return distribution of an error of signal (in our case of a signal $z(z *=0))$.

B. If parameter $0<\tilde{q}_{2}<1$ then in real time occurs further training of neural network and at the same time neuro-indistinct control parametrically of an uncertain physical object of the known structure.

B. If the parameter $\tilde{q}_{2}=1$ then process of training of network comes to an end, and the $\mathrm{NN}$ works as the ordinary adaptive regulator $\left(\tilde{q}_{1}=0\right)$.

Conditions A $-\mathrm{B}$ represent the system of production rules (production) and are implemented in the decision-making block (DMB) of the associative automatic machine of adaptive management [6].

\section{Parametrical Synthesis Of The Stabilizing Control On The Basis Of The Method Of The High-Speed Gradient And The Theory Of The Sliding Modes}

As an effective algorithm of the return distribution in article it is offered to use the method of a highspeed gradient (MHSG) [17].

The formulation of a problem of synthesis of the stabilizing control of MSG is as follows.

The state of $j$-th TM is $x \in R^{n}$, control $u$ is scalar, it is observed scalar $z=c^{T} x \in R^{1}$. Evolution of $j$-th TM is described by differential system $\left(1^{*}\right)$ where the measured piecewise and differentiable function $\sigma(t, z, u)$ is additive additive to scalar control $u$ and is subordinated to restriction of a look (4), $B$ is constant $n$-vector of the configured input parameters (coefficients of synoptic communications of single-layer $\mathrm{NN}$ ). control linearly depends on observed size: $u=L z$.

The matrix $A$ and vector $B$ are in advance unknown. The vector $c$ considering "deposits" of state variables $x$ to observation $z$ is set.

It is required to synthesize the parametric regulator $L=L(t)$.

The control purpose is execution of condition $\lim _{t \rightarrow \infty} x(t)=\overrightarrow{0}$ corresponds to minimization in a limit $t \rightarrow \infty$

of a local functional $J(t)=0,5 x^{T} H x$ where $H$ is positively certain symmetric matrix of dimensionality $n \times n$.

We will apply the diagram MSG in the differential form to synthesis of the non-linear parametric regulator [17].

For this purpose we will define a total derivative from a local functionality

$\dot{J}(t)=0,5\left(x^{T} H \dot{x}+\dot{x}^{T} H x\right)=x^{T} H\left[\left(A+L B c^{T}\right) x+B\left(\frac{\tilde{q}_{1} \alpha}{L}+\tilde{q}_{2} \beta L\right)\right]$ ,also we will calculate a gradient in parameter $L$ 


$$
\nabla_{L} \varphi(x, L)=x^{T} H B\left(z-\frac{\tilde{q}_{1} \alpha}{L^{2}}+\tilde{q}_{2} \beta\right) .
$$

According to the scheme MSG the nonlinear scalar regulator synthesized in a differential form has an appearance

$$
\dot{L}=-\gamma \nabla_{L} \varphi(x, L) .
$$

For system $\left(1^{*}\right),(2),(3)$ at restrictions for FA (4) type an algorithm of adaptation (training) $j$-th TM registers in a look

$$
\dot{L}=-\gamma x^{T} H B\left(z-\frac{\tilde{q}_{1} \alpha}{L^{2}}+\tilde{q}_{2} \beta\right),
$$

where $\gamma>0$ is the positive number determining the speed of decrease of a gradient by parameter $L$. In (11) we will demand respect for equality

$$
H B=c
$$

Then taking into account that $c^{T}=B^{T} H$, in a final look we will receive an adaptation algorithm of $j$-th TM

$$
\dot{L}=-\gamma\left(z-\frac{\tilde{q}_{1} \alpha}{L^{2}}+\tilde{q}_{2} \beta\right) z
$$

where $\tilde{q}_{2} \in[0,1], \quad \tilde{q}_{1}=1-\tilde{q}_{2}$ are the parameters defining the NN operating mode.

The formula (13) is fair in areas for which $L>L^{+}, L<L^{-}$, and function $\sigma(L)$ is close to linear dependence. The parametrical regulator $L$ in these areas of change of an argument is quasilinear one.

In the area limited to vertical $L^{ \pm}$and horizontal $\sigma^{ \pm}$asymptotes of function $\sigma(L)$ there are sliding modes for which ensuring asymptotic stability at measurement $r$ of the first phase coordinates instead of formulas (3), (13) of the parametrical regulator the law of control with explosive coefficients is used [19, page 249]. In our case for the solution of a problem of stabilization we adopt $r=1$ also the law of management of a look

$$
\begin{gathered}
u=-L z-\delta_{u}, \quad L= \begin{cases}L^{+}, & z s>0, \\
L^{-}, & z s<0,\end{cases} \\
\delta_{u}=\left\{\begin{array}{cc}
\delta_{0}, & s>0, \\
-\delta_{0}, & s<0,
\end{array} \delta_{0}=\left|\delta_{0}\right| \operatorname{sign}\left(c^{\frac{1}{Y}}\right)\right.
\end{gathered}
$$

Here $\delta_{0}$ is as much as small number, other than zero, which sign coincides with the sign of a scalar $c^{T} B$ and the surface of switching is defined by the second factor of a formula (13):

$$
s(z)=z-\frac{\tilde{q}_{1} \alpha}{L^{2}}+\tilde{q}_{2} \beta .
$$

The derivative on time from function $s$ owing to the equations (16) has an appearance

$$
\dot{s}(z)=\dot{z}+\frac{3 \tilde{q}_{1} \alpha}{L^{3}} \dot{L} .
$$

Conditions of implementation of sliding at axiomatic approach are defined by inequalities [19]:

$$
\dot{s}^{+}=\lim _{s(x) \rightarrow+0} \dot{s}<0, \dot{s}^{-}=\lim _{s(x) \rightarrow-0} \dot{s}>0 .
$$

The specified conditions (18) separate from each other variety $\dot{s}^{+}=0$ or $\dot{s}^{-}=0$, or generally $\dot{s}=0$.

The condition of hit of the representing point on the surface of sliding has an appearance [19]

$$
s(z) \dot{s}(z)<0 \text {. }
$$

also corresponds to conditions (9) of the theorem 3. Inclusion in the law of control (14) of small composed $\delta_{u}$ is caused by the fact that at $r<n-1$ ( $n$ is order of differential system (1)) on the surface of switching $s(z)=0$ in points in which the measured size and its derivatives $\left(z_{i}=0\right.$ ( $i=1,2, \ldots, r)$ take place of equality: $\dot{s}^{+}=\lim \dot{s}=0, \dot{s}^{-}=\lim \dot{s}=0$. Therefore $s(x) \rightarrow+0 \quad s(x) \rightarrow-0$

if in our case to accept $\delta_{u}=0(i=1)$, then at hit to the vicinity $z_{1}=z=0$ the representing point can not direct to position of balance or at hit in the beginning of coordinates can move away from balance position.

The required variety $\dot{s}(z)=0$ is defined from a formula (17)

$$
\dot{s}(z)=\dot{z}+\frac{3 \tilde{q}_{1} \alpha}{L^{3}} \dot{L}=0 .
$$

Considering that in the field of the sliding modes in case of $L=L^{+}$or $L=L^{-}$the law of control (13) takes a form

$$
\dot{L}=-\gamma z^{2}
$$

after substitution of a formula (21) in equality (20) we will receive the equation of the sliding movement

$$
\dot{z}=\frac{3 \tilde{q}_{1} \alpha \gamma}{L^{3}} z^{2}
$$

where parameter $L=L^{ \pm}$according to a formula (14) accepts one of possible values $L^{+}$or $L^{-}$.

The solution of the equation of the sliding movement (22) can be received in an analytical look through variables separation

$$
\frac{d z}{z^{2}}=\frac{3 \tilde{q}_{1} \alpha \gamma}{\left(L^{ \pm}\right)^{3}} d t
$$

after integration of his right and left parts 
$z=\frac{\left(L^{ \pm}\right)^{3}}{3 \tilde{q}_{1} \alpha \gamma t}+C= \pm \frac{\lambda_{1}}{t}+C$

where $\lambda_{1}=\frac{\left(\left|L^{ \pm}\right|\right)^{3}}{3 \tilde{q}_{1} \alpha \gamma}$ is the varied proportionality coefficient, $C$ are the constants determined by various entry conditions $z(0)$.

Family of curves (23) represent functions of inversely proportional dependences $z=f(t)$ on time. The analysis of these curves shows what at $t \rightarrow \infty$ function $z$ tends to zero. Thereby at the organization of the sliding movement the adaptation objectives are achieved: $\lim _{t \rightarrow \infty} z(t)=z *=0$ on a system exit ( $\left.1^{*}\right)$, (2), (3) in a problem of stabilization. As at observed size, owing to the equations (21), (3) in the field of the sliding modes the parameter and management also tend to zero.

The phase portrait of the movement of the representing point according to the equation of the sliding movement (22) is defined by family of the parabolas $\dot{z}=f(z)= \pm \lambda_{2} z^{2}, \quad$ symmetric concerning an axis $z$ up and down. Here $\lambda_{2}=\frac{3 \tilde{q}_{1} \alpha \gamma}{\left(\left|L^{ \pm}\right|\right)^{3}}$ is the varied proportionality coefficient.

Thus, achievement by system $\left(1^{*}\right),(2),(3)$ on an exit $z$ of the natural purpose of adaptation: $\lim z(t)=z *=0$ i.e. achievement of a limited limit $t \rightarrow \infty$

set, defines the main property of adaptive systems dissipativity [17, with. 403]. In our case the property of dissipativity provides roughness of system to external indignations due to introduction of a zone of tolerance $\sigma^{ \pm}$to functions $\sigma(L)$, roughness of system to parametrical indignations due to introduction of a zone of tolerance $L^{ \pm}$of parameter of the regulator $L$ and roughness of system to dynamic indignations due to introduction of additional feedback on an exit $z$.

For providing the Gurvitz's property of closed parametrical regulator (3) systems $\left(1^{*}\right),(2)$ (the theorem 2) it is necessary to define the general algorithm of adaptation defined from the analysis of a formula (13). It is easy to see that the Gurvitz's property of a matrix $A *=A+L B c^{T}$ remains if in the adaptation block in the form of production the following logical conditions are satisfied:

A) control is formed directly on a formula (13) that corresponds to a quasilinear operating mode of the adaptive neural regulator; B) if

$\left(L^{-}<L<L^{+}\right) \cap(z<0), \quad$ then $\dot{L}<0 \quad$ and management is formed on formulas (14) - (16) which define the sliding operating mode of the neural regulator.

Production rules A), B) are also implemented in BPR of the associative automatic machine of adaptive management [6].

\section{Initialization of Entry Conditions}

Realization stability conditions of the zero solution of the equations of $j$-th TM (condition b) of the theorems 1 or the investigations of the theorem 2) for achievement of the goal of adaptation $\lim _{t \rightarrow \infty} x(t)=\overrightarrow{0}$ comes down to initialization of entry $t \rightarrow \infty$

conditions of an algorithm of adaptation (13).

Initialization of entry conditions of an algorithm of adaptation (13) is as follows [16].

1). Using a Mat Lab Toolbox LMI package, by method of linear programming we solve the system of matrix inequalities of Lyapunov

$$
H A *+A_{*}^{T} H<0
$$

also we define a matrix $H$.

2). Being set by scales $c=c *$ of output signals $x_{k}(k=\overline{1, n})$, from a formula (12) we calculate parameters of a vector $B$ of NBP: $B=H^{-1} c *$.

$3)$. Applying a stability condition) theorems 1 , we define an entry condition $L(0)$ of algorithm of adaptation (13) $\left(\tilde{q}_{1}=1, \tilde{q}_{2}=0\right): L(0)=-\alpha \frac{c_{*}^{T} B}{z(0)}$.

In the subsequent entry conditions of an algorithm of adaptation (13) are specified in real time with the step equal to the sampling period (an observation interval) of an output signal $z$.

Alternative way of preliminary initialization of the NN parameters on an algorithm of the return distribution - use of a Neural Toolbox package of the Mat Lab environment [10, 11].

Further expeditious training and control of $j$-th TM is made by on algorithm of adaptation (13) ( $\left.0<\tilde{q}_{2}<1\right)$. At $\tilde{q}_{2}=1$ process of training of $\mathrm{NN}$ comes to end and the NN works as usual AR.

\section{Conclusion}

Thus, in article on the basis of the organization of parametric control for a method of a high-speed gradient and the theory of systems with variable structure the effective algorithm of adaptation allowing is developed:

$\left.\left\{\left(L>L^{-}\right) \cap\left(L>L^{+}\right) \cap(z>0)\right\} \cup\left\{\left(L<L^{+}\right) \cap\left(L<L^{-}\right) \cap(z>0)\right\}\right)$ to accelerate convergence neuro-indistinct control or $\left(L>L^{+}\right) \cap\left(L<L^{-}\right) \cap(z<0)$, то $\dot{L}<0$ and due to training of a neural network in real time; 
2) to apply hybrid networks on which artificial neural networks communicate with structures of the adaptive control on the basis of traditional technologies;

3) to realize preliminary training and to apply effective procedures of initialization of parameters of a neural network.

For implementation of an algorithm of adaptation on the basis of a one-layer neural network there are enough knowledge of an order of the differential equations describing a physical entity with steady structure of correlations between its elements.

Unlike traditional adaptive approach when the area of steady solutions of the linear part of system $\left(1^{*}\right)$ is defined by a condition $L<0$, in case of the organization of neurosimilar structures area of admissible parameter values $L$ of the regulator is all set of the real numbers $L \in R^{1}$.

\section{References}

1. Nikiforov A.D., Kovshov A.N., Nazarov Iu.F. Protsessy upravleniia ob"ektami mashinostroeniia [Engineering Management Processes]. Moscow, Vysshaia shkola [High school], 2001. 455 p.

2. Bazrov B.M. Modul'nye tekhnologiia v mashinostroenii [Modular technology in mechanical engineering]. Moscow, Mashinostroenie, 2001. 368 p.

3. Fradkov A.L. O primenenii kiberneticheskikh metodov $\mathrm{v}$ fizike [About using of cybernetic methods in physics]. Uspekhi fizicheskikh nauk, 2005, vol. 175, no. 2, pp. 113-138.

4. Ma C., Zhang J. Necessary and Sufficient Conditions for Consensusability of Linear Multi-agent Systems. IEEE Transactions of Automatic Control, 2010, vol. 55, no. 5, pp. 1263-1268.

5. Scardovi L., Sepulchre R. Synchronization in Networks of Identical Linear Systems. Automatica, 2009, vol. 45, no. 10, pp. 2557-2562.

6. Pashkov N.N., Mukhopad Iu.F., PunsykNamzhilov D.Ts. Assotsiativnyi avtomat detsentra-lizovannogo adaptivnogo upravleniia sistemoi avtonomnykh vychislitel'nykh protsessov [Associative automatic adaptive control system of decentralized autonomous computational processes]. Nauchnyi vestnik NGTU [Scientific Journal of NSTU]. Novosibirsk, 2009, no. 2 (35), pp. 201-206.

7. Bukov V.N. Vlozhenie sistem. Analiticheskii podkhod $\mathrm{k}$ analizu i sintezu matrichnykh system [Attachment of systems. An analytical approach to the analysis and synthesis of matrix systems]. Kaluga: Izd-vo N.F. Bochkareva, 2006, $720 \mathrm{p}$.

8. Nascak D., Kerekanic J., Husarova M. Advanced System for Technological Process Control. European Scientific Journal. London, 2013, vol. 9, no. 36, pp. 176-186.

9. Omatu S., Khalid M., Iusof R. NeuroControl and its Applications. SpringerVerlag London Limited, 1996. 272 p. ( Russ. Ed.: Neiroupravlenie i ego prilozheniia. Kn. 2 // Neirokontrol-lery i ikh primenenie / Pod red. A.I. Galushkina, V.A. Ptichkina. Moscow, IPRZhR, 2000. $272 \mathrm{p}$.

10. Krylov A.A., Sizykh V.N., Chumak A.G. Metodika strukturno-parametricheskogo sinteza neirosetevoi modeli prodol'nogo dvizheniia vozdushnogo transportnogo sredstva [Technique of structuralparametric synthesis of neural network model for longitudinal movement of the air vehicle]. Zhurnal «Sovremennye tekhnologii. Sistemnyi analiz. Modelirovanie» [Modern technologies. System analysis. Modeling]. Irkutsk, 2011, no. 1(29), pp. 129-134.

11. Krylov A.A., Ozerov V.N., Sizykh V.N. Neirosetevaia sistema avtomaticheskogo upravleniia samoletom $\mathrm{v}$ rezhime dempfirovaniia [Neural network autopilot system in damping mode]. Vestnik Voronezhskogo gos. tekhn. un-ta [Scientific Journal of VSTU]. Voronezh, 2011, vol. 7, no. 1, pp. 189-194.

12. Liang J., Harley R.G., Venayagamoorthy G.K. Adaptive Critical Design Based Dynamic Optimal Power Flow Controller for Smart Grid. Proc. 2011 IEEE Symposium Series on Computational Intelligence - Computer Intelligence Applications in Smart Grid (CIASG). Paris, France, Apr. 11-15, 2011.

13. Aizerman M.A. O skhodimosti protsessa regulirovaniia posle bol'shikh nachal'nykh otklonenii [Convergence of regulatory process after large initial variance]. A $i T$ [Automation and Remove Control]. 1946, no. 2-3, pp. 148-167.

14. Gil' M.I. Ob odnom klasse absoliutno ustoichivykh system [About one class of absolutely stable systems]. $A \quad i \quad T$ 
[Automation and Remove Control]. 1983, no. 10. pp. 27-36.

15. Sragovich V.G. Adaptivnoe upravlenie [Adaptive control]. Moscow, Nauka, 1981. $384 \mathrm{p}$.

16. Mukhopad Iu.F., Pashkov N.N., Sizykh V.N. Adaptivnyi podkhod $\mathrm{k}$ neironnomu upravleniiu odnim klassom absoliutno ustoichivykh system [Adaptive approach to neuro-control of one class of absolutely stable systems]. Zhurnal "Fundamental'nye issledovaniia" [Fundamental research]. Moscow.: Izd-vo RAE. 2011, no. 8, pp. 139-147.

17. Fomin V.N., Fradkov A.L., Iakubovich V.A. Adaptivnoe upravlenie dinamicheskimi ob"ektami [Adaptive control of dynamic objects]. Moscow, Nauka, Glavnaia redaktsiia fiz.-mat. lit., 1981. $448 \mathrm{p}$.

18. Sizykh V.N., Shlykova I.A. Adaptivnoe neiroupravlenie tipovym tekhnologicheskim modulem na osnove metoda skorostnogo gradienta [Adaptive neuro-control for model technological module on bases of the high-speed gradient method]. Mezhregional'nyi sovet po nauke $i$ tekhnologiiam (MSNT). Mekhanika $i$ protsessy upravleniia. Materialy XXXXI Vserossiiskogo simpoziuma [The interregional Council of science and technology (MCST). Mechanics and control processes. Proc. of the XXXXI AllRussian Symposium]. Moscow, RAN [Russian science academy], 2011, vol. 2, pp. 246-255

19. Kim D.P. Teoriia avtomaticheskogo upravleniia. T. 2. Mnogomernye, nelineinye, opti-mal'nye i adaptivnye sistemy [Theory of automatic control. Vol. 2. Multidimensional, nonlinear, optimal and adaptive systems]. Moscow, FIZMATLIT, 2004. $464 \mathrm{p}$.

20. Mukhopad Iu.F., Mukhopad A.Iu. Metody sinteza samokontroliruemykh avtomatov [The synthesis methods of itself control automatic systems]. Problemy informatiki [Problems of Informatics]. Novosibirsk: Izd-vo SO RAN, 2012, no. 1(13), pp. 17 28. 